\title{
Association between chromosomal aberration of exfoliated bladder cells in the urine and oxidative stress in patients with bladder transitional cell carcinoma
}

\author{
DONG WANG $^{1 *}$, JIA-FU FENG $^{2 *}$, GUANG-YA YUAN ${ }^{3}$, YONG-HONG YANG $^{4}$, \\ YUN-SHUANG LIU ${ }^{2}$ and YU-WEI YANG ${ }^{2}$ \\ Departments of ${ }^{1}$ Oncology, ${ }^{2}$ Clinical Laboratory, ${ }^{3}$ Urology and ${ }^{4}$ Pathology, \\ Mianyang Central Hospital, Affiliated to Southwest Medical University, Mianyang, Sichuan 621000, P.R. China
}

Received September 19, 2015; Accepted March 9, 2017

DOI: $10.3892 / \mathrm{ol} .2017 .6128$

\begin{abstract}
The aim of the current study was to investigate the chromosomal aberrations of exfoliated bladder cells in the urine and blood oxidative stress in patients with bladder transitional cell carcinoma (BTCC). A total of 40 healthy controls and 246 patients with BTCC were recruited. Abnormal levels of CSP3, CSP7, CSP17 and GLPp16 were detected by fluorescence in situ hybridization (FISH) in exfoliated bladder cells in the urine of patients with BTCC. Serum total oxidant status (TOS), total antioxidant status (TAS) and oxidative stress index (OSI) were measured. Significant differences were observed in the abnormal CSP3, CSP7, CSP17, GLPp16 signals and FISH positive rate between patients with BTCC and healthy controls $(\mathrm{P}<0.001)$. Serum TOS, TAS and OSI were also significantly different between the two groups $(\mathrm{P}<0.001)$. The clinical stage of BTCC was not associated with abnormal CSP3, CSP7, CSP17, GLPp16 or FISH positive rate and oxidative stress $(\mathrm{P}>0.05)$. A Gamma rank correlation analysis revealed an association between the pathological grade of BTCC with abnormal CSP3, CSP7 and CSP17 as well as FISH positive rate $(\mathrm{P}<0.001)$. In addition, the clinical stage of BTCC was associated with serum TOS, TAS and OSI $(\mathrm{P}<0.001)$. Evaluation of the association between chromosomal
\end{abstract}

Correspondence to: Professor Jia-Fu Feng, Department of Clinical Laboratory, Mianyang Central Hospital, Affiliated to Southwest Medical University, 12 ChangjiaXiang, Jingzhong Street, Fucheng, Mianyang, Sichuan 621000, P.R. China

E-mail: fengjiafudoc@163.com

*Contributed equally

Abbreviations: AUC, area under curve; BTCC, bladder transitional cell carcinoma; DAPI, 4,6-diamidino-2-phenylindole; FISH, fluorescence in situ hybridization; OSI, oxidative stress index; OxS, oxidative stress; ROS, reactive oxygen species; SSC, saline sodium citrate; TAS, total antioxidant status; TOS, total oxidant status

Key words: BTCC, FISH, OxS, diagnosis aberrations and oxidative stress revealed that abnormal CSP3, CSP7 and CSP17 were positively associated with serum TOS and OSI $(\mathrm{P}<0.001)$, abnormal CSP7 and CSP17 were negatively associated with serum TAS $(\mathrm{P}<0.001)$, but abnormal GLPp16 was not associated with serum TOS, TAS or OSI ( $\mathrm{P}>0.05)$. Therefore, the chromosomal aberrations of exfoliated bladder cells in the urine are associated with blood oxidative stress in patients with BTCC, and these factors may contribute to the occurrence and development of BTCC.

\section{Introduction}

Bladder cancer is a common malignancy of the urinary system. According to the American Cancer Society, bladder cancer was the fourth most common cancer and the eighth leading cause of cancer-associated mortality in men in 2015, and its incidence and mortality accounted for 7 and $4 \%$ of female patients with tumors, respectively (1). The morbidity and mortality of bladder cancer is lower in women than men, and is ranked greater than tenth, for mortality, of all types of female cancer $(2,3)$. In China, the incidence of bladder cancer is slightly lower, and it ranks the eighth most common malignancy in males (4). The majority of types of bladder cancer are of epithelial origin, of which $\sim 90 \%$ of cases are bladder transitional cell carcinoma (BTCC) with a papillary appearance (5).

The carcinogenesis of bladder cancer is very complex, in which genetic mutations and epigenetic alterations serve important roles $(2,3,6,7)$. Furthermore, inflammation and oxidative damage contribute to the occurrence and progression of bladder cancer $(6,8,9)$. Cellular oxidative damage is primarily caused by reactive oxygen species (ROS) (10), which have been implicated in the pathogenesis of a number of diseases $(11,12)$. Oxidative stress $(\mathrm{OxS})$ is caused by the excessive production of oxidants (including ROS and free radicals) and/or a reduction of antioxidants in the target cells and tissues (13). OxS may cause damage to proteins, lipids and DNA, which is a critical pathophysiological event implicated in a number of human pathologies, including cancer $(12,13)$. Increased $\mathrm{OxS}$ has been demonstrated in patients with bladder cancer (14-18). However, previous studies have primarily focused on a single or several oxidants/antioxidants $(9,19-22)$, 
whereas the overall OxS status has not been widely studied. Thus, it is difficult to fully elucidate the association between the pathogenesis of bladder cancer and overall serum OxS (10-12).

The molecular and genetic changes that occur during the pathogenesis of BTCC can be divided into three steps: The first step is chromosomal alteration, which triggers the initial carcinogenic event; the second is cancer cell proliferation due to loss of cell-cycle regulation and dysregulation of normal apoptotic turnover; the third is cancer metastasis, which involves cell migration, angiogenesis and loss of cell adhesion (23). It has been confirmed that there are associations between genetic mutations and BTCC, and some genes associated with BTCC have been extensively investigated in previous studies (24-27). There is evidence that the cyclin-dependent kinase inhibitors p 21 and p16 are associated with the increased recurrence and progression of cancer (23). Additionally, the pathogenesis and/or progression of BTCC have been demonstrated to be a consequence of genetic instability, and chromosomes 3, 7,9 and 17 are involved in uroepithelial oncogenesis (28-30). Fluorescence in situ hybridization (FISH) is a sensitive method that can be used to detect chromosomal abnormalities in exfoliated bladder cells and to evaluate of BTCC malignancy.

In the present study, FISH was performed to detect levels of CSP3, CSP7, CSP17 and GLPp16 of exfoliated bladder cells in the urine. In addition, serum OxS was determined in patients with BTCC, with the aim of evaluating the association between genetic changes and $\mathrm{OxS}$ in these patients.

\section{Materials and methods}

Subjects. A total of 246 patients were recruited from the Department of Urology of Mianyang Central Hospital (Mianyang, China) between June 2008 and May 2014. All patients were initially diagnosed with BTCC or had recurrent BTCC and their diagnoses were based on cystoscopy with urinary cytology. There were 192 males and 54 females with a mean age of $61.3 \pm 11.7$ years (range, 35-87 years). According to the International Union Against Cancer TNM classification system (31) and World Health Organization criteria (32), patients were classified as stage Ta ( 24 cases), T1 (75 cases), T2 (74 cases), T3 (48 cases) and T4 (25 cases), and as G0 ( 35 cases), G1 (57 cases), G2A (72 cases), G2B (52 cases) and G3 (30 cases). In addition, 40 healthy volunteers ( 33 males and 7 females; mean age $58.8 \pm 15.4$ years; age range, $31-73$ years) were also recruited as controls. These volunteers from the same region were confirmed to be healthy and without history of cardiovascular, kidney, hepatic, pulmonary, hematological, gastrointestinal, metabolic, endocrine, immunological, neurological and/or psychiatric diseases. Healthy subjects had no history of drug and food hypersensitivity and they had not undergone any drug treatment. Furthermore, the pregnancy and lactation individuals also were excluded. No significant differences were identified in the age $(\mathrm{t}=-1.195, \mathrm{P}=0.233)$ and gender $\left(\chi^{2}=0.406, P=0.524\right)$ between patients with BTCC and controls. The present study was approved by the Medical Ethics Committee of Mianyang Central Hospital (Mianyang, China) and written informed consent was obtained from all subjects.

\section{Sample collection}

Urine collection. The urine from the first urination of healthy control subjects was collected in the morning for three consecutive days (1,500 ml daily). The first washing buffer (200-400 ml) was collected from patients with BTCC at cystoscopy. Both urine and washing buffer were used as urine samples for FISH.

Blood collection. Following cystoscopy in patients with BTCC and the last urination in healthy controls, venous blood $(\sim 5 \mathrm{ml})$ was collected into BD Vacutainer ${ }^{\circledR}$ Serum Tubes (BD Biosciences, Franklin Lakes, NJ, USA). Serum was separated by centrifugation at $1,600 \mathrm{x} \mathrm{g}$ at room temperature for $15 \mathrm{~min}$ within $2 \mathrm{~h}$ after sample collection and then stored at $-30^{\circ} \mathrm{C}$; experiments were carried out within $48 \mathrm{~h}$. Serum was used for measuring total oxidant status (TOS) and total antioxidant status (TAS).

\section{Measurement of OxS parameters}

$T A S$. TAS was determined colorimetrically using the Total Antioxidant Status ${ }^{\circledR}$ kit (Randox Laboratories, Ltd., Crumlin, UK). In this assay, 2,2'-azino-di-3-ethylbenz-thiazoline sulfonate was incubated with a peroxidase (metmyoglobin) and hydrogen peroxide to produce the radical cation 2,2'-azino-di-3-ethylbenz-thiazoline sulfonate ${ }^{+}$. This forms a relatively stable blue-green color solution, which was measured using a 7600-020 automatic biochemical analyzer (Hitachi, Ltd., Tokyo, Japan) at $600 \mathrm{~nm}$. The assay was calibrated with a $1.65 \mathrm{mmol} / \mathrm{l}$ Trolox standard. TAS results were expressed as mmol Trolox equivalent/l (mmol Trolox Eq./l).

TOS. The TOS level in serum was measured using a modification of automated colorimetric method with the 7600-020 automatic biochemical analyzer (33). In this method, the ferrous ions were oxidized to ferric ions in the presence of various oxidants in an acidic medium. Ferric ion concentrations were determined using xylenol orange. TOS measurements were performed using the following instrument settings: Method, end-point measurement; serum, $10 \mu \mathrm{l}$; reagent 1, $200 \mu \mathrm{l}$; reagent $2,50 \mu \mathrm{l}$; reaction time, $10 \mathrm{~min}$; temperature, $37^{\circ} \mathrm{C}$; primary wavelength, $560 \mathrm{~nm}$; secondary wavelength, $800 \mathrm{~nm}$; and reading point, 34. A known concentration hydrogen peroxide of $39.16 \mu \mathrm{mol} / 1$ was used as the standard to calculate oxidant levels in the samples. TOS values were expressed in $\mu$ mol $\mathrm{H}_{2} \mathrm{O}_{2}$ equivalent/l $\left(\mu\right.$ mol $\mathrm{H}_{2} \mathrm{O}_{2}$ Eq./l).

Oxidative stress index (OSI). The ratio percentage of TOS-to-TAS potential gave OSI $(34,35)$, which was calculated as follows: OSI (arbitrary unit, $\mathrm{AU})=[(\mathrm{TOS}, \mu \mathrm{mol}$ $\mathrm{H}_{2} \mathrm{O}_{2}$ Eq./l)/(TAS, $\mu$ mol TroloxEq./l)]x100 (36).

\section{Interphase FISH analysis}

Slide preparation. A total of $\sim 40 \mathrm{ml}$ freshly voided urine (the first urination of the day) was added to $50 \mathrm{ml}$ Falcon centrifuge tubes. Cells of voided urine were separated by centrifugation at $1,500 \mathrm{x}$ g for $10 \mathrm{~min}$ at room temperature. A fraction of supernatant was removed and $\sim 1 \mathrm{ml}$ of supernatant and cell sediment were left in the tube. Glacial acetic acid (2-3 ml) was added, and the mixture was subjected to constant agitation for $\sim 10 \mathrm{sec}$ at room temperature and then diluted with normal saline twice. The diluted mixture was centrifuged at $1,500 \mathrm{x} \mathrm{g}$ for $5 \mathrm{~min}$ at room temperature, the supernatant was removed, and the cells were re-suspended and added onto a clean slide 
at 3 locations. To ensure appropriate cell density, 3, 10, and $30 \mu \mathrm{l}$ of cell suspension were added to the slide. Fresh Carnoy's fixative (methanol-to-glacial acetic acid ratio, 3:1; v/v) was added to cell sediment, which was mixed and resuspended. Fresh fixative was added again and the cells were mixed and stored at $-20^{\circ} \mathrm{C}$ for $30 \mathrm{~min}$. The slides were air-dried at room temperature.

The slides used for FISH analysis were treated with $2 \mathrm{x}$ saline sodium citrate (SSC) buffer for $2 \mathrm{~min}$ at $73^{\circ} \mathrm{C}$ and then with $0.075 \mathrm{~mol} / 1$ protease for $10 \mathrm{~min}$ at $37^{\circ} \mathrm{C}$, washed in PBS for $5 \mathrm{~min}$ at room temperature, fixed in $1 \%$ formaldehyde for $5 \mathrm{~min}$ at room temperature, and washed again in PBS for $5 \mathrm{~min}$ at room temperature. The slides were dehydrated in a series of ethanol solutions $(70,85$, and $100 \% ; 1$ min for each) at room temperature and then air-dried completely.

Denaturation and hybridization. A specific probe kit (F01008-00; Beijing GP Medical Technologies, Ltd., Beijing, China) was used in the study and included CEP3, CEP7 (both labeled with rhodamine), CEP17 and GLPp16 (both labeled with fluorescein isothiocyanate) probes. The probe mixtures were composed of $7.0 \mu \mathrm{l}$ hybrid buffer, $1.0 \mu \mathrm{l}$ deionized water and $2.0 \mu \mathrm{l}$ of probe; thus, each antibody probe was diluted $5 \mathrm{X}$. In brief, $10 \mu \mathrm{l}$ of probe mixture was added to each cell sediment on the slide, followed by mounting with a small glass coverslip and sealing with rubber cement. The target DNA and probe were placed in the StatSpin ${ }^{\circledR}$ ThermoBrite Slide Denaturation and Hybridization System (Iris Sample Processing, Inc., Westwood, MA, USA) for denaturation at $73^{\circ} \mathrm{C}$ for $5 \mathrm{~min}$ and then hybridization at $37^{\circ} \mathrm{C}$ for $16 \mathrm{~h}$.

The rubber cement and coverslip were removed following hybridization. The slides were washed with $50 \%$ formamide, 2X SSC and $0.1 \% \mathrm{NP}-40$ in $2 \mathrm{X} \mathrm{SSC}$ for $2 \mathrm{~min}$ at $46^{\circ} \mathrm{C}$ to remove unbound probes. The slides were transferred to room temperature and washed in $70 \%$ ethyl alcohol for $1 \mathrm{~min}$ to remove NP-40 and subsequently air-dried. After $1 \mathrm{~min}, 10 \mu \mathrm{l}$ of DAPI was added to the target area, and coverslips were mounted. The slides were stored in the dark at $-20^{\circ} \mathrm{C}$ until signal quantification.

Analysis of signals. Interphase nuclei were analyzed with a fluorescence microscopy imaging system (Imstar S.A., Paris, France) to determine the numbers of each chromosome. The following criteria were used to select 100 nuclei for each probe: Cells with large nuclei; nuclear shape irregularity, patchy DAPI staining, and clustering. Cell nuclei were identified using the DAPI filter. Squamous cells, neutrophils, umbrella cells and inflammatory cells were not counted. Only non-overlapping cells with distinct signals were scored. The number of signals was determined and recorded for all 4 probes. If chromosomes 3,7 , or 17 exhibited the loss of the two signals (red and green), the cell was considered to be un-interpretable owing to hybridization failure. If the cell exhibited abnormal signals in $\geq 2$ chromosomes, the cell was considered abnormal.

A total of 40 voided urine samples from healthy subjects were used to establish the cut-off values that were defined as mean and 3 standard deviations (mean $+3 \mathrm{SD}$ ) of the percentage of nuclei with abnormal signals (Table I). Specimens were considered FISH positive if they had abnormalities that include daneusomy of locus-specific probes, chromosome monosomy and polysomy, and only when the percentage of cells with 1 or $\geq 3$ FISH signals for each chromosome were higher than the cut-off values.

Statistical analysis. Count data are expressed as percentage, and rates were compared using a $\chi^{2}$ test. Quantitative data are expressed as the mean \pm SD. A Spearman's rank correlation analysis was performed to evaluate the association between FISH data and OxS, and Gamma rank correlation analysis (for count data) or Spearman's rank correlation analysis (for quantitative data) was performed to assess the association of FISH data and $\mathrm{OxS}$ with clinical stage and grade. Statistical analyses were performed with PASW Statistics software (version 18.0; IBM SPSS, Armonk, NY, USA) and MedCalc statistical software (version 11.5; MedCalc Software, Mariakerke, Belgium). $\mathrm{P}<0.05$ was considered to indicate a statistically significant difference.

\section{Results}

Chromosomal aberrations and $O x S$. The chromosomal aberrations of exfoliated bladder cells and blood OxS are illustrated in Table II. The proportions of abnormal CSP3, CSP7, CSP17 and GLPp16, and FISH positive rates were 50.4, 53.3, 44.7, 60.2 and $54.5 \%$, respectively, in patients with BTCC, which were significantly higher compared with healthy controls $\left(\chi^{2}\right.$ test, $\left.\mathrm{P}<0.01\right)$. The serum TOS and OSI were $18.56 \pm 3.72$ and $1.35 \pm 0.43 \mu \mathrm{mol} \mathrm{H}_{2} \mathrm{O}_{2} \mathrm{Eq} . /$, respectively, in patients with BTCC, which were significantly higher compared with those of healthy controls $(\mathrm{P}<0.001)$. However, the serum TAS in patients with BTCC $(1.44 \pm 0.23$ mmolTroloxEq./l) was significantly lower compared with that of healthy controls $(\mathrm{P}<0.001)$.

Hybridization signals of exfoliated bladder cells of BTCC patients. The typical hybridization signals of CSP3, CSP7, CSP17 and GLPp16 in exfoliated bladder cells of patients with BTCC are presented in Fig. 1. Of 246 patients, 217 (88.2\%) patients had at least one abnormal hybridization signals, exhibiting mixed missing, haploid and polyploidy cells (Table III). In the present study, abnormal CSP3, CSP7 and CSP17 signals were typically associated with polyploidy, whereas abnormal GLPp16 signals were typically associated with haploid cells.

OxS status of BTCC patients. OxS parameters were analyzed using a receiver operating characteristic curve. The results demonstrated that when the cut-off values of TOS, TAS and ISO were $16.82 \mu \mathrm{mol} \mathrm{H}_{2} \mathrm{O}_{2}$ Eq./1, $1.60 \mathrm{mmol}$ Trolox Eq./l and $1.04 \mathrm{AU}$, respectively. The diagnostic performance reached the highest level of diagnostic accuracy: The sensitivity was 61.4, 78.5 and $71.1 \%$, respectively; the specificity was $97.5,62.5$ and $95.0 \%$, respectively; area under curve (AUC) was 0.812, 0.768 and 0.871 , respectively $(\mathrm{z}=11.555,7.103$ and 16.715 , respectively; all $\mathrm{P}<0.001$; Fig. 2). No significant differences were identified between $\mathrm{AUC}_{\mathrm{TOS}}$ and $\mathrm{AUC}_{\mathrm{TAS}}(\mathrm{z}=1.067, \mathrm{P}=0.286)$, but significant differences were observed between $\mathrm{AUC}_{\mathrm{OSI}}$ and $\mathrm{AUC}_{\mathrm{TOS}}(\mathrm{z}=2.671, \mathrm{P}=0.008)$ or between $\mathrm{AUC}_{\mathrm{OSI}}$ and $\mathrm{AUC}_{\mathrm{TAS}}$ $(\mathrm{z}=3.566, \mathrm{P}<0.001)$.

Correlation between chromosomal aberrations and OxS inpatients with BTCC. The FISH data and OxS parameters 
Table I. Optimal cut-off values for fluorescence in situ hybridization-positive voided urine specimens $(\mathrm{n}=30)$.

\begin{tabular}{lccr}
\hline Probe & 0 signal $(\%)$ & 1 signal $(\%)$ & $\geq 3$ signals $(\%)$ \\
\hline CSP3 & - & $0.37 \pm 0.72,2.53$ & $1.07 \pm 1.82,6.53$ \\
CSP7 & - & $0.40 \pm 0.81,2.83$ & $1.10 \pm 1.39,5.27$ \\
GLPp16 & $1.27 \pm 1.11,4.60$ & $1.03 \pm 1.61,5.86$ & $0.73 \pm 0.83,3.22$ \\
CSP17 & - & $0.67 \pm 0.92,3.43$ & $1.60 \pm 1.52,6.16$
\end{tabular}

Data were presented as the mean $\pm \mathrm{SD}$ and the cut-off value, and this cut-off value is equal to mean $+3 \mathrm{SD}$. SD, standard deviation .

Table II. FISH of exfoliated bladder cells, and oxidative stress of patients with BTCC and healthy controls.

\begin{tabular}{|c|c|c|c|c|}
\hline Parameter & BTCC group & Control group & $\chi^{2}$ or t-test value & P-value \\
\hline Total, $\mathrm{n}$ & 246 & 40 & & \\
\hline CSP3, n (\%) & $124(50.4)$ & $4(10.0)$ & $21.115^{\mathrm{a}}$ & $<0.001$ \\
\hline CSP7, n (\%) & $131(53.3)$ & $5(12.5)$ & $21.305^{\mathrm{a}}$ & $<0.001$ \\
\hline CSP17, n (\%) & $110(44.7)$ & $3(7.5)$ & $18.411^{\mathrm{a}}$ & $<0.001$ \\
\hline GLPp16, n (\%) & $148(60.2)$ & $7(17.5)$ & $23.537^{\mathrm{a}}$ & $<0.001$ \\
\hline FISH, n (\%) & $134(54.5)$ & $0(0.0)$ & $38.839^{\mathrm{a}}$ & $<0.001$ \\
\hline Total oxidant status, $\mu \mathrm{mol} \mathrm{H}_{2} \mathrm{O}_{2}$ Eq./l & $18.56 \pm 3.72$ & $14.64 \pm 1.29$ & $6.604^{\mathrm{b}}$ & $<0.001$ \\
\hline Total antioxidant status, mmol Trolox Eq./l & $1.44 \pm 0.23$ & $1.65 \pm 0.17$ & $-5.623^{b}$ & $<0.001$ \\
\hline Oxidative stress index & $1.35 \pm 0.43$ & $0.89 \pm 0.11$ & $6.669^{\mathrm{b}}$ & $<0.001$ \\
\hline
\end{tabular}

${ }^{a} \chi^{2}$ test. ${ }^{b}$-test. BTCC, bladder transitional cell carcinoma; FISH, fluorescence in situ hybridization.

Table III. Hybridization signals in exfoliated bladder cells of 246 patients with bladder transitional cell carcinoma.

\begin{tabular}{lccc}
\hline Probe & Mixed missing (0 or 1 signal) & Haploid (1 signal) & Polyploid (>3 signals) \\
\hline CSP3, n (\%) & $6(2.4)$ & $12(4.9)$ & $106(43.1)$ \\
CSP7, n (\%) & $12(4.9)$ & $15(6.1)$ & $104(42.3)$ \\
CSP17, n (\%) & $10(4.1)$ & $25(10.2)$ & $75(30.5)$ \\
GLPp16, n (\%) & $27(11.0)$ & $110(44.7)$ & $11(4.5)$
\end{tabular}

of patients with BTCC at different clinical stages and pathological grades are illustrated in Table IV. The correlation of proportions of different chromosomal aberrations and FISH positive rate with the clinical stage and grade of BTCC were evaluated with Gamma rank correlation analysis. The proportions of abnormal CSP3, CSP7 and CSP17 and FISH positive rate were not correlated with the clinical stage of BTCC ( $r=0.131,0.118,0.1384$ and -0.014 , respectively; all $\mathrm{P}>0.05)$, but were positively correlated with pathological grade $(\mathrm{r}=0.515,0.639,0.584$ and 0.413 , respectively, all $\mathrm{P}<0.001)$; the proportion of abnormal GLPp16 was not correlated with clinical stage $(\mathrm{r}=-0.026, \mathrm{P}=0.792)$ or pathological grade $(\mathrm{r}=0.063, \mathrm{P}=0.497)$.

A Spearman's rank correlation analysis was employed to evaluate the correlation of $\mathrm{OxS}$ parameters with clinical stage and pathological grade of BTCC. Serum TOS, TAS and OSI were not correlated with clinical stage $(\mathrm{P}>0.05)$, but the pathological grade was positively correlated with serum TOS $(\mathrm{r}=0.671, \mathrm{P}<0.001)$ and OSI $(\mathrm{r}=0.660, \mathrm{P}<0.001)$ and negatively to serum TAS $(\mathrm{r}=-0.326, \mathrm{P}<0.001)$.

Correlation between chromosomal aberrations and serum OxS parameters. A Spearman's rank correlation analysis revealed that abnormal CSP3, CSP7 and CSP17 signals were positively correlated with TOS and OSI (all $\mathrm{P}<0.001$ ), and abnormal CSP7 and CSP17 signals were negatively correlated with TAS (both $\mathrm{P}<0.001)$. However, GLPp16 signals were not correlated with TOS, TAS or OSI (all P>0.05; Table V).

\section{Discussion}

Bladder cancer is a common malignancy of the urinary system that affects individuals worldwide. The pathogenesis of bladder cancer is complex and involves a number of factors at multiple steps, including intrinsic genetic factors and extrinsic environmental factors $(2,37)$. Thus, evaluating the correlation 

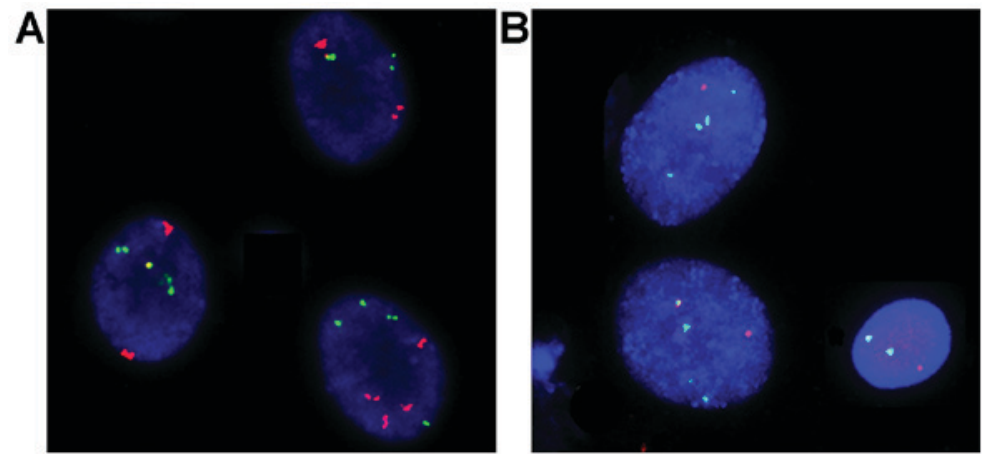

Figure 1. Representative fluorescence in situ hybridization image of exfoliated bladder cells from patients with bladder transitional cell carcinoma (magnification, x1000). (A) CSP3 (red), CSP7 (green), CSP3 or CSP7 triploidy/tetraploidy was observed in this patient. (B) CSP17 (green), GLPp16 (red), CSP17 diploidy/triploidy/tetraploidy and GLPp16 haploid deletion were observed in this patient.

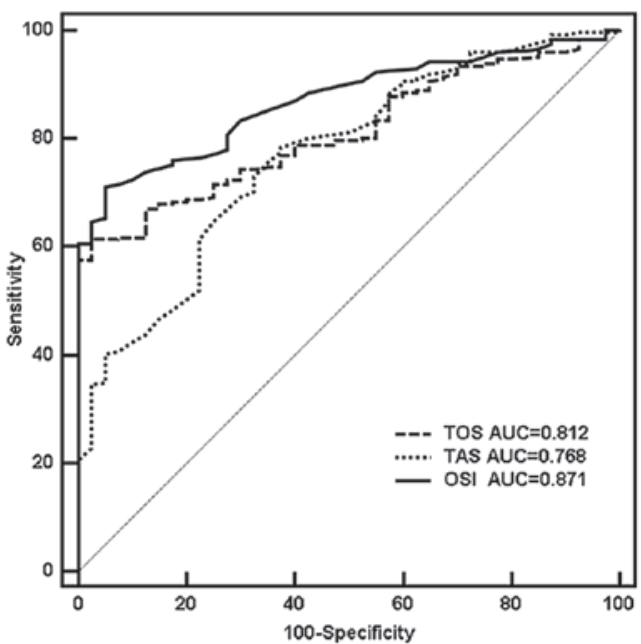

Figure 2. Diagnostic performance of serum oxidative stress parameters for bladder transitional cell carcinoma. No significant difference was identified between $\mathrm{AUC}_{\mathrm{TOS}}$ and $\mathrm{AUC}_{\mathrm{TAS}}(\mathrm{z}=1.067, \mathrm{P}=0.286)$, but significant differences were observed between $\mathrm{AUC}_{\mathrm{OSI}}$ and $\mathrm{AUC}_{\mathrm{TOS}}(\mathrm{z}=2.671, \mathrm{P}=0.008)$ or between $\mathrm{AUC}_{\mathrm{OSI}}$ and $\mathrm{AUC}_{\mathrm{TAS}}(\mathrm{z}=3.566, \mathrm{P}<0.001)$. TOS, total oxidant status; TAS, total antioxidant status; OSI, oxidative stress index; AUC, area under curve.

between genetic variation at chromosomes and oxidative stress is crucial for the elucidation of the molecular mechanisms underlying the occurrence and development of bladder cancer.

Abnormal chromosomal structure and number are typical characteristics of cancer cells, which have been confirmed in numerous genetic studies (27-29). Thus, these abnormal characteristics may be used for the diagnosis of cancers. FISH of bladder tissues or exfoliated bladder cells is effective for identifying chromosomal aberrations, including structural aberration and/or number aberration (28,29,37-40). The US Food and Drug Administration approved UroVysion ${ }^{\circledR}$ multicolor-FISH (Abbott Laboratories, Abbott Park, IL, USA) for the detection of exfoliated cells in the urine, which is a non-invasive tool used for the adjunctive diagnosis of bladder cancer $(39,40)$. In the present study, FISH similar to UroVysion ${ }^{\circledR}$ was performed to detect chromosomal aberrations in exfoliated bladder cells of patients with BTCC, and blood oxidative stress was also evaluated. The results demonstrated that the proportions of abnormal CSP3, CSP7, CSP17 and GLPp16 signals in exfoliated bladder cells were significantly increased compared with in healthy controls $(\mathrm{P}<0.001)$, and all of them were positively associated with the pathological grade of BTCC $(\mathrm{P}<0.001)$. This suggests that the specific probes used in the present study can be used for the non-invasive early diagnosis of BTCC and the monitoring of post-operative recurrence of BTCC. In addition, hyperdiploidy of exfoliated bladder cells was positively associated with the progression of BTCC, indicating that this tool may be used to determine the severity of BTCC.

Oxidative stress is caused by the excess production of ROS and/or increased consumption of antioxidants in target cells and tissues. Previous studies have demonstrated that oxidative stress serves important roles in the occurrence, development and metastasis of bladder cancer (14-18). However, these studies primarily focused on one or several oxidative products, antioxidants or their metabolites $(9,19-22)$, and the oxidative stress levels were predicted according to the change in these products. This evaluation is not comprehensive, as the changes in one or several oxidative products or antioxidants may not represent the overall status of oxidative stress. In addition, oxidants/antioxidants may interact with each other, leading to overlapping effects $(41,42)$, and there are unknown oxidants/antioxidants that were not detectable in these studies. Thus, findings in these studies may not comprehensively and systematically evaluate the oxidative stress. TAS represents a sum of enzyme and non-enzyme antioxidants, and TOS reflects the overall level of oxidants (43). In the present study, TAS and TOS were measured and OSI was calculated, which may reflect the overall oxidative stress status. The results from the present study demonstrated that the serum TOS $(\mathrm{t}=6.604, \mathrm{P}<0.001)$ and OSI $(\mathrm{t}=6.669, \mathrm{P}<0.001)$ in patients with BTCC were significantly higher compared with that of healthy controls. However, serum TAS $(\mathrm{t}=-5.623, \mathrm{P}<0.001)$ was significantly lower compared with that of healthy controls, suggesting the oxidative stress induced injury in patients with BTCC. Analysis using a receiver operating characteristic curve demonstrated that these OxS parameters were able to distinguish patients with BTCC from healthy controls (AUC $=0.812$, 0.768 and 0.871 , respectively; all $\mathrm{P}<0.001)$. Further analysis revealed that the AUC of OSI was higher than that of TOS and TAS, indicating that OSI is superior to TOS and TAS in the diagnosis of BTCC. Correlation analysis demonstrated that these OxS parameters were associated with the pathological 
Table IV. Correlation between chromosomal aberrations and oxidative stress parameters in patients with bladder transitional cell carcinoma.

Clinical stage

\begin{tabular}{|c|c|c|c|c|c|c|c|}
\hline \multirow[b]{2}{*}{ A, Group } & \\
\hline & $\mathrm{Ta}$ & $\mathrm{T} 1$ & $\mathrm{~T} 2$ & $\mathrm{~T} 3$ & $\mathrm{~T} 4$ & R-value & P-value \\
\hline Total, n & 24 & 75 & 74 & 48 & 25 & & \\
\hline $\mathrm{CSP}^{\mathrm{a}}, \mathrm{n}(\%)$ & $8(33.3)$ & $39(52.0)$ & $33(44.6)$ & $34(70.8)$ & $10(40.0)$ & 0.131 & 0.155 \\
\hline $\mathrm{CSP}^{\mathrm{a}}, \mathrm{n}(\%)$ & $9(37.5)$ & $41(54.7)$ & $36(48.6)$ & $34(70.8)$ & $11(44.0)$ & 0.118 & 0.207 \\
\hline $\mathrm{CSP} 17^{\mathrm{a}}, \mathrm{n}(\%)$ & $5(20.8)$ & $31(41.3)$ & $43(58.1)$ & $20(41.7)$ & $11(44.0)$ & 0.138 & 0.133 \\
\hline GLPp16a, n (\%) & $9(37.5)$ & $49(65.3)$ & $50(67.6)$ & $33(68.8)$ & $7(28.0)$ & -0.026 & 0.792 \\
\hline $\mathrm{FISH}^{\mathrm{a}}, \mathrm{n}(\%)$ & $6(25.0)$ & $49(65.3)$ & $44(59.5)$ & $23(47.9)$ & $12(48.0)$ & -0.014 & 0.885 \\
\hline $\mathrm{TOS}^{\mathrm{b}}, \mu \mathrm{mol} \mathrm{H} \mathrm{O}_{2}$ Eq. $/ 1$ & $16.68 \pm 3.28$ & $18.98 \pm 3.96$ & $18.56 \pm 3.32$ & $17.52 \pm 3.94$ & $20.61 \pm 3.02$ & 0.087 & 0.175 \\
\hline TAS $^{\mathrm{b}}$, mmol Trolox Eq./1 & $1.45 \pm 0.26$ & $1.45 \pm 0.23$ & $1.42 \pm 0.21$ & $1.49 \pm 0.18$ & $1.34 \pm 0.32$ & -0.043 & 0.502 \\
\hline $\mathrm{OSI}^{\mathrm{b}}, \mathrm{AU}$ & $1.22 \pm 0.49$ & $1.36 \pm 0.42$ & $1.34 \pm 0.36$ & $1.19 \pm 0.32$ & $1.66 \pm 0.57$ & 0.093 & 0.146 \\
\hline
\end{tabular}

Pathological grade

\begin{tabular}{|c|c|c|c|c|c|c|c|}
\hline \multirow[b]{2}{*}{ B, Group } & \\
\hline & G0 & G1 & $\mathrm{G} 2 \mathrm{~A}$ & $\mathrm{G} 2 \mathrm{~B}$ & G3 & R-value & P-value \\
\hline Total, $\mathrm{n}$ & 35 & 57 & 72 & 52 & 30 & & \\
\hline $\mathrm{CSP}^{\mathrm{a}}, \mathrm{n}(\%)$ & $4(11.4)$ & $27(47.4)$ & $33(45.8)$ & $36(69.2)$ & $24(80.0)$ & 0.515 & $<0.001$ \\
\hline $\mathrm{CSP}^{\mathrm{a}}, \mathrm{n}(\%)$ & $8(22.9)$ & $16(28.1)$ & $41(56.9)$ & $39(75.0)$ & $27(90.0)$ & 0.639 & $<0.001$ \\
\hline $\mathrm{CSP} 17^{\mathrm{a}}, \mathrm{n}(\%)$ & $8(22.9)$ & $12(21.1)$ & $32(44.4)$ & $32(61.5)$ & $26(86.7)$ & 0.584 & $<0.001$ \\
\hline GLPp $16^{\mathrm{a}}, \mathrm{n}(\%)$ & $19(54.3)$ & $37(64.9)$ & $37(51.4)$ & $38(73.1)$ & $17(56.7)$ & 0.063 & 0.497 \\
\hline $\mathrm{FISH}^{\mathrm{a}}, \mathrm{n}(\%)$ & $10(28.6)$ & $28(49.1)$ & $38(52.8)$ & $31(59.6)$ & $27(90.0)$ & 0.413 & $<0.001$ \\
\hline $\mathrm{TOS}^{\mathrm{b}}, \mu \mathrm{mol} \mathrm{H} \mathrm{O}_{2} \mathrm{Eq} . / \mathrm{l}$ & $14.58 \pm 1.33$ & $16.16 \pm 2.47$ & $19.35 \pm 3.15$ & $20.79 \pm 3.34$ & $22.00 \pm 2.42$ & 0.671 & $<0.001$ \\
\hline TAS $^{\mathrm{b}}$, mmol Trolox Eq./1 & $1.52 \pm 0.23$ & $1.54 \pm 0.19$ & $1.43 \pm 0.19$ & $1.37 \pm 0.24$ & $1.27 \pm 0.28$ & -0.326 & $<0.001$ \\
\hline $\mathrm{OSI}^{\mathrm{b}}, \mathrm{AU}$ & $0.98 \pm 0.17$ & $1.07 \pm 0.24$ & $1.38 \pm 0.29$ & $1.55 \pm 0.36$ & $1.84 \pm 0.54$ & 0.66 & $<0.001$ \\
\hline
\end{tabular}

${ }^{\mathrm{a}} \mathrm{Gamma}$ rank correlation analysis; ${ }^{\mathrm{b}}$ Spearman's rank correlation analysis. FISH, fluorescence in situ hybridization; TOS, total oxidant status; TAS, total antioxidant status; OSI, oxidative stress index.

Table V. Spearman's rank correlation analysis of fluorescent in situ hybridization data and serum oxidative stress parameters.

\begin{tabular}{lccrr}
\hline Parameter & CSP3 & CSP7 & CSP17 & GLPp16 \\
\hline Total oxidant status & $0.248,<0.001$ & $0.351,<0.001$ & $0.304,<0.001$ & $0.047,0.461$ \\
Total antioxidant status & $-0.122,0.057$ & $-0.297,<0.001$ & $-0.182,<0.001$ & $-0.015,0.821$ \\
Oxidative stress index & $0.237,<0.001$ & $0.435,<0.001$ & $0.317,<0.001$ & $0.018,0.781$ \\
\hline
\end{tabular}

Data were presented as R-value, P-value.

grade of BTCC $(\mathrm{R}=0.671$ for TOS, -0.326 for TAS and 0.660 for OSI; all $\mathrm{P}<0.001)$, indicating that $\mathrm{OxS}$ parameters may be used to evaluate the clinical progression of BTCC. Thus, serum OxS parameters used in the present study may accurately reflect the oxidative stress status, and may be used to differentiate between BTCC and healthy status in addition to evaluating the disease condition. Notably, serum TAS was inferior to TOS and OSI in the diagnosis of BTCC, and its cut-off value (1.60 mmol Trolox Eq./l) was located in the reference range of healthy control (1.48-1.82 mmol Trolox Eq./l), which resulted in poor sensitivity $(78.5 \%)$ and poor specificity
(62.5\%). These findings indicate that detecting antioxidant levels alone fails to comprehensively evaluate the oxidative stress status, and that it is necessary to detect TAS and TOS in addition to calculating OSI for the scientific and rational evaluation of oxidative stress status.

Previous studies have revealed that radiation, smoking, long-lasting chronic infection and stimulation of foreign bodies are factors that are associated with bladder cancer $(44,45)$. These factors may change the oxidative stress status, cause DNA oxidation, activate oncogenes $(46,47)$ inactivate tumor suppressor genes, induce the occurrence of bladder cancer and promote its 
progression $(48,49)$. A number of FISH techniques have been developed for the investigation of DNA oxidative damage in tissues and cells in patients with bladder cancer $(39,50,51)$. In the present study, the correlation between blood OxS parameters and chromosomal aberrations of exfoliated bladder cells was evaluated. The results demonstrated that the serum TOS and OSI were positively associated with abnormal CSP3, CSP7 and CSP17 $(\mathrm{P}<0.001)$ and parameters reflecting the proliferation of cancer cells. However, serum TAS was negatively associated with abnormal CSP7 and CSP17 ( $<<0.001)$. This suggests that the oxidative stress status in patients with BTCC is associated with chromosomal aberrations of bladder cells. Notably, the OxS parameters detected in the present study were not associated with abnormal GLPp16 $(\mathrm{P}>0.05)$. p16 is a tumor suppressor gene and may act on p16-INK4a to regulate the p38-mitogen activated protein kinase signaling pathway, which then regulates the expression of downstream genes, regulates the ROS production in cells, inhibits excess proliferation and mediates the apoptosis of cells, avoiding carcinogenesis $(52,53)$. Dysregulated p16 during carcinogenesis fails to control the intracellular production of ROS and is unable to effectively regulate oxidative stress, which explains the absence of correlation between abnormal GLPp16 and blood oxidative stress.

In conclusion, chromosomal alterations are typical in patients with bladder cancer, which can be detected via FISH. Oxidative stress may cause damage to protein, lipid, and DNA and has been revealed to be a critical pathophysiological event implicated in numerous human diseases, including cancer. Thus, in the present study, the correlation between chromosomal alterations and oxidative stress status was explored, which may aid with the elucidation of mechanisms underlying the occurrence and development of bladder cancer and the determination of the severity of BTCC. However, the molecular mechanisms underlying the association between chromosomal alterations and oxidative stress status remain unclear, and it is probable that the two facilitate the occurrence and development of cancer. Therefore, studies on the association between the two may provide reliable theoretical evidence for the prevention and treatment of cancer.

\section{Acknowledgements}

The present study was supported by the Ministry of Science and Technology of the People's Republic of China (grant no. 2006AA020905) and the Ministry of Health of the People's Republic of China (grant no. WKJ2007-3-001).

\section{References}

1. Siegel RL, Miller KD and Jemal A: Cancer statistics, 2015. CA Cancer J Clin 65: 5-29, 2015.

2. Torre LA, Bray F, Siegel RL, Ferlay J, Lortet-Tieulent J and Jemal A: Global cancer statistics, 2012. CA Cancer J Clin 65: 87-108, 2015

3. Figueroa JD, Ye Y, Siddiq A, Garcia-Closas M, Chatterjee N, Prokunina-Olsson L, Cortessis VK, Kooperberg C, Cussenot O, Benhamou S, et al: Genome-wide association study identifies multiple loci associated with bladder cancer risk. Hum Mol Genet 23: 1387-1398, 2014.

4. Wang Z, Lu T, Du L, Hu Z, Zhuang Q, Li Y, Wang CY, Zhu H and Ye Z: Plasmacytoid urothelial carcinoma of the urinary bladder: A clinical pathological study and literature review. Int J Clin Exp Pathol 5: 601-608, 2012.
5. Kanojia D, Garg M, Saini S, Agarwal S, Parashar D, Jagadish N, Seth A, Bhatnagar A, Gupta A, Kumar R, et al: Sperm associated antigen 9 plays an important role in bladder transitional cell carcinoma. PLoS One 8: e81348, 2013.

6. Patchsung M, Boonla C, Amnattrakul P, Dissayabutra T, Mutirangura $\mathrm{A}$ and Tosukhowong P: Long interspersed nuclear element-1 hypomethylation and oxidative stress: Correlation and bladder cancer diagnostic potential. PLoS One 7: e37009, 2012.

7. Redondo-Gonzalez E, de Castro LN, Moreno-Sierra J, Maestro de las Casas ML, Vera-Gonzalez V, Ferrari DG and Corchado JM: Bladder carcinoma data with clinical risk factors and molecular markers: A cluster analysis. Biomed Res Int 2015: 168682, 2015.

8. Gakis G: The role of inflammation in bladder cancer. Adv Exp Med Biol 816: 183-196, 2014.

9. Gecit I, Aslan M, Gunes M, Pirincci N, Esen R, Demir H and Ceylan K: Serum prolidase activity, oxidative stress, and nitric oxide levels in patients with bladder cancer. J Cancer Res Clin Oncol 138: 739-743, 2012.

10. Wang X, Li S, Liu Y and Ma C: Redox regulated peroxisome homeostasis. Redox Biol 4: 104-108, 2015.

11. Le Lay S, Simard G, Martinez MC and Andriantsitohaina R: Oxidative stress and metabolic pathologies: From an adipocentric point of view. Oxid Med Cell Longev 2014: 908539, 2014.

12. Thanan R, Oikawa S, Hiraku Y, Ohnishi S, Ma N, Pinlaor S, Yongvanit P, Kawanishi S and Murata M: Oxidative stress and its significant roles in neurodegenerative diseases and cancer. Int J Mol Sci 16: 193-217, 2014.

13. Chaudhari N, Talwar P, Parimisetty A, Lefebvre d'Hellencourt C and Ravanan P: A molecular web: Endoplasmic reticulum stress, inflammation, and oxidative stress. Front Cell Neurosci 8: 213, 2014

14. Deng H, Lv L, Li Y, Zhang C, Meng F, Pu Y, Xiao J, Qian L, Zhao W, Liu Q, et al: miR-193a-3p regulates the multi-drug resistance of bladder cancer by targeting the LOXL4 gene and the oxidative stress pathway. Mol Cancer 13: 234, 2014.

15. Higgins JA, Zainol M, Brown K and Jones GD: Anthocyans as tertiary chemopreventive agents in bladder cancer: Anti-oxidant mechanisms and interaction with mitomycin C. Mutagenesis 29: 227-235, 2014.

16. Ellidag HY, Eren E, Aydin O, Akgol E, Yalcinkaya S, Sezer C and Yilmaz N: Ischemia modified albumin levels and oxidative stress in patients with bladder cancer. Asian Pac J Cancer Prev 14: 2759-2763, 2013.

17. Savic-Radojevic A, Djukic T, Simic T, Pljesa-Ercegovac M, Dragicevic D, Pekmezovic T, Cekerevac M, Santric V and Matic M: GSTM1-null and GSTA1-low activity genotypes are associated with enhanced oxidative damage in bladder cancer. Redox Rep 18: 1-7, 2013.

18. Amasyali AS, Kucukgergin C, Erdem S, Sanli O, Seckin S and Nane I: Nitric oxide synthase (eNOS4a/b) gene polymorphism is associated with tumor recurrence and progression in superficial bladder cancer cases. J Urol 188: 2398-2403, 2012.

19. Soini Y, Haapasaari KM, Vaarala MH, Turpeenniemi-Hujanen T, Kärjä V and Karihtala P: 8-hydroxydeguanosine and nitrotyrosine are prognostic factors in urinary bladder carcinoma. Int J Clin Exp Pathol 4: 267-275, 2011.

20. Yilmaz IA, Akçay T, Cakatay U, Telci A, Ataus S and Yalçin V: Relation between bladder cancer and protein oxidation. Int Urol Nephrol 35: 345-350, 2003.

21. Badjatia N, Satyam A, Singh P, Seth A and Sharma A: Altered antioxidant status and lipid peroxidation in Indian patients with urothelial bladder carcinoma. Urol Oncol 28: 360-367, 2010.

22. Yalçin O, Karataş F, Erulaş FA and Ozdemir E: The levels of glutathione peroxidase, vitamin A, E, C and lipid peroxidation in patients with transitional cell carcinoma of the bladder. BJU Int 93: 863-866, 2004.

23. Abat D, Demirhan O, Inandiklioglu N, Tunc E, Erdogan S, Tastemir D, Uslu IN and Tansug Z: Genetic alterations of chromosomes, p53 and p16 genes in low- and high-grade bladder cancer. Oncol Lett 8: 25-32, 2014.

24. Lopez-Beltran A, Santoni M, Massari F, Ciccarese C, Tortora G, Cheng L, Moch H, Scarpelli M, Reymundo C and Montironi R: Bladder cancer: Molecular determinants of personalized therapy. Curr Drug Targets 16: 115-124, 2015.

25. Drayton RM, Peter S, Myers K, Miah S, Dudziec E, Bryant HE and Catto JW: MicroRNA-99a and 100 mediated upregulation of FOXA1 in bladder cancer. Oncotarget 5: 6375-6386, 2014. 
26. Wieczorek E, Wasowicz W, Gromadzinska J and Reszka E: Functional polymorphisms in the matrix metalloproteinase genes and their association with bladder cancer risk and recurrence: A mini-review. Int J Urol 21: 744-752, 2014.

27. Morrison CD, Liu P, Woloszynska-Read A, Zhang J, Luo W, Qin M, Bshara W, Conroy JM, Sabatini L, Vedell P, et al: Whole-genome sequencing identifies genomic heterogeneity at a nucleotide and chromosomal level in bladder cancer. Proc Natl Acad Sci USA 111: E672-E681, 2014.

28. Campos SR, Melo TC, Assaf S, Araldi RP, Mazzuchelli-deSouza J, Sircili MP, Carvalho RF, Roperto F, Beçak W and Stocco RC: Chromosome aberrations in cells infected with bovine papillomavirus: Comparing cutaneous papilloma, esophagus papilloma, and urinary bladder lesion cells. ISRN Oncol 2013: 910849, 2013.

29. Köhler CU, Martin L, Bonberg N, Behrens T, Deix T, Braun K, Noldus J, Jöckel KH, Erbel R, Sommerer F, et al: Automated quantification of FISH signals in urinary cells enables the assessment of chromosomal aberration patterns characteristic for bladder cancer. Biochem Biophys Res Commun 448: 467-472, 2014.

30. Bonberg N, Taeger D, Gawrych K, Johnen G, Banek S, Schwentner C, Sievert KD, Wellhäußer H, Kluckert $M$, Leng $\mathrm{G}$, et al: Chromosomal instability and bladder cancer: The UroVysion(TM) test in the UroScreen study. BJU Int 112: E372-E382, 2013.

31. Sobin L, Gospodarowicz M and Wittekind C: TNM Classification of Malignant Tumours. Urological Tumours. Renal Pelvis and Ureter. Wiley-Blackwell, 2009.

32. Barnes L, Eveson JW, Reichart P and Sidransky D: World Health Organization classification of tumours: Pathology and genetics of head and neck tumours. Lyon: IARC: 168-175, 2005.

33. Erel O: A new automated colorimetric method for measuring total oxidant status. Clin Biochem 38: 1103-1111, 2005.

34. Harma M, Harma M and Erel O: Oxidative stress in women with preeclampsia. Am J Obstet Gynecol 192: 656-657, 2005.

35. Aycicek A, Erel O and Kocyigit A: Decreased total antioxidant capacity and increased oxidative stress in passive smoker infants and their mothers. Pediatr Int 47: 635-639, 2005.

36. Aycicek A and Erel O: Total oxidant/antioxidant status in jaundiced newborns before and after phototherapy. J Pediatr (Rio J) 83 319-322, 2007.

37. Dwivedi AN, Jain S and Dixit R: Gall bladder carcinoma: Aggressive malignancy with protean loco-regional and distant spread. World J Clin Cases 3: 231-244, 2015.

38. Kwak KW, Kim SH and Lee HM: The utility of fluorescence in situ hybridization for detection of bladder urothelial carcinoma in routine clinical practice. J Korean Med Sci 24: 1139-1144, 2009.

39. Caraway NP, Khanna A, Fernandez RL, Payne L, Bassett RL Jr, Zhang HZ, Kamat A and Katz RL: Fluorescence in situ hybridization for detecting urothelial carcinoma: A clinicopathologic study. Cancer Cytopathol 118: 259-268, 2010.
40. Caraway NP and Katz RL: A review on the current state of urine cytology emphasizing the role of fluorescence in situ hybridization as an adjunct to diagnosis. Cancer Cytopathol 118: 175-183, 2010.

41. Feng JF, Lu L, Zeng P, Yang YH, Luo J, Yang YW and Wang D: Serum total oxidant/antioxidant status and trace element levels in breast cancer patients. Int J Clin Oncol 17: 575-583, 2012.

42. Wang D, Feng JF, Zeng P, Yang YH, Luo J and Yang YW: Total oxidant/antioxidant status in sera of patients with thyroid cancers. Endocr Relat Cancer 18: 773-782, 2011.

43. Cumurcu BE, Ozyurt H, Etikan I, Demir S and Karlidag R: Total antioxidant capacity and total oxidant status in patients with major depression: Impact of antidepressant treatment. Psychiatry Clin Neurosci 63: 639-645, 2009.

44. Salim EI, Morimura K, Menesi A, El-Lity M, Fukushima S and Wanibuchi $\mathrm{H}$ : Elevated oxidative stress and DNA damage and repair levels in urinary bladder carcinomas associated with schistosomiasis. Int J Cancer 123: 601-608, 2008.

45. Vadhanam MV, Thaiparambil J, Gairola CG and Gupta RC: Oxidative DNA adducts detected in vitro from redox activity of cigarette smoke constituents. Chem Res Toxicol 25: 2499-2504, 2012.

46. Bellavia M, Gioviale MC, Damiano G, Palumbo VD, Spinelli G, Buscemi $G$ and Lo Monte AI: Dissecting the different biological effects of oncogenic Ras isoforms in cancer cell lines: Could stimulation of oxidative stress be the one more weapon of H-Ras? Regulation of oxidative stress and Ras biological effects. Med Hypotheses 79: 731-734, 2012.

47. Guo S, Mao X, Chen J, Huang B, Jin C, Xu Z and Qiu S: Overexpression of Pim-1 in bladder cancer. J Exp Clin Cancer Res 29: 161, 2010.

48. Li S, Peng Q, Chen Y, You J, Chen Z, Deng Y, Lao X, Wu H, Qin $X$ and Zeng Z: DNA repair gene XRCC1 polymorphisms, smoking, and bladder cancer risk: A meta-analysis. PLoS One 8: e73448, 2013

49. Yang D, Liu C, Shi J, Wang N, Du X, Yin Q and Wang Y: Association of XRCC1 Arg399Gln polymorphism with bladder cancer susceptibility: A meta-analysis. Gene 534: 17-23, 2014.

50. McKenna DJ, Doherty BA, Downes CS, McKeown SR and McKelvey-Martin VJ: Use of the comet-FISH assay to compare DNA damage and repair in p53 and hTERT genes following ionizing radiation. PLoS One 7: e49364, 2012.

51. Ke Z, Lai Y, Ma X, Lil S and Huang W: Diagnosis of bladder cancer from the voided urine specimens using multi-target fluorescence hybridization. Oncol Lett 7: 325-330, 2014.

52. Jenkins NC, Liu T, Cassidy P, Leachman SA, Boucher KM, Goodson AG, Samadashwily G and Grossman D: The p16 (INK4A) tumor suppressor regulates cellular oxidative stress. Oncogene 30: 265-274, 2011.

53. Rayess H, Wang MB and Srivatsan ES: Cellular senescence and tumor suppressor gene p16. Int J Cancer 130: 1715-1725, 2012. 